\title{
Conceitos de ecologia aplicada: biodiversidade e gestão de interferências ambientais
}

A razão para conservar a biodiversidade depende do valor que damos às espécies individuais. Este valor surge de muitas considerações relativas ao nosso próprio interesse e envolvimento. Para muitas pessoas, a extinção levanta uma questão moral. Alguns tomam essa posição porque se a espécie humana afeta toda a natureza, é nossa responsabilidade moral protegê-la. Se a moralidade origina-se de uma lei natural - isto é, se a moralidade é intrínseca à vida propriamente dita, então podemos presumir que aos direitos dos indivíduos e espécies não humanos são tão legítimos quanto os dos indivíduos da sociedade humana.

Palavras-chave: Ecologia aplicada; Biodiversidade; Interferências ambientais.

\section{Concepts of applied ecology: biodiversity and environmental interference management}

The reason for conserving biodiversity depends on the value we place on individual species. This value arises from many considerations regarding our own interest and involvement. For many people, extinction raises a moral issue. Some take this position because if the human species affects the whole of nature, it is our moral responsibility to protect it. If morality stems from a natural law - that is, if morality is intrinsic to life itself - then we can assume that the rights of individuals and non-human species are as legitimate as those of individuals in human society.

Keywords: Applied ecology; Biodiversity; Environmental interference.

Topic: Notas Científicas

Reviewed anonymously in the process of blind peer
Received: 10/05/2021

Approved: 20/06/2021
Lais Alencar de Aguiar (iD

Universidade Federal do Rio de Janeiro, Brasil

http://lattes.cnpq.br/5785500333245448

https://orcid.org/0000-0002-1551-4085

aguiar.lais@gmail.com

Josimar Ribeiro de Almeida (D)

Universidade Federal do Rio de Janeiro, Brasil

http://lattes.cnpq.br/3215586187698472

https://orcid.org/0000-0001-5993-0665

almeida@poli.ufrj.br

Cleber Vinicius Vitorio da Silva

Universidade Federal do Rio de Janeiro, Brasil

http://lattes.cnpq.br/4275890458575782

https://orcid.org/0000-0001-8337-9615

clebervitorio88@gmail.com
Elenice Rachid da Silva Lenz

Universidade Federal do Rio de Janeiro, Brasil

http://lattes.cnpq.br/4557023865361858

erachid@pet.coppe.ufrj.br
Referencing this:

AGUIAR, L. A.; ALMEIDA, J. R.; SILVA, C. V. V.; LENZ, E. R. S.. Conceitos de ecologia aplicada: biodiversidade e gestão de interferências ambientais. Natural Resources, v.11, n.2, p.138-143, 2021. DOI:

http://doi.org/10.6008/CBPC2237-9290.2021.002.00015 


\section{INTRODUÇÃO}

Naturalmente, a nenhuma espécie é garantido o direito à existência perpétua, assim como a nenhum humano é garantido o direito à imortalidade. Mas a extinção através da irrestrita caça, poluição e destruição de habitat, e disseminação irresponsável de doenças pode ser análoga ao assassinato, à carnificina, ao genocídio e outras infrações aos direitos humanos individuais. Às vezes podemos questionar a conservação de um tipo de habitat comparando o valor econômico das espécies nativas que lá ocorrem e o valor advindo da alteração ou outro manejo do habitat. Sob muitas circunstâncias, contudo, o ganho de curto prazo de converter florestas em agricultura, por exemplo, ou de um recurso marinho excessivamente explorado, é assumido sobrepujar qualquer valor de longo prazo de conservar o sistema natural para uma receita sustentável.

O valor de espécies e habitat conservados usualmente torna-se evidente quando os custos de longo prazo da sobre exploração ou conversão do habitat são apropriadamente levados em conta, uma prática que não é encorajada pelo pragmatismo do desespero nem pela notória visão curta dos políticos. É útil distinguir entre três tipos de extinção. A extinção de fundo (background extinction) reflete o fato de que à medida que o ambiente muda, algumas espécies desaparecem e outras tomam seus lugares. Esta troca de espécies, numa taxa relativamente baixa, parece ser uma característica normal dos sistemas naturais. A extinção em massa refere-se à morte de um grande número de espécies como resultado de catástrofes naturais.

Os vulcões, furacões e impactos de meteoros acontecem ocasionalmente. Alguns ocorrem localmente, outros afetam o globo inteiro, e as espécies que acontecem estar no caminho desaparecem. As extinções antropogênicas - aquelas causadas por humanos - são similares às extinções em massa no número da taxa de afetados, nas dimensões globais e na natureza catastrófica de tais eventos. A extinção antropogênica difere da extinção em massa, contudo no sentido de que naquela as causas estão sob nosso controle. A maior parte da informação sobre extinções de fundo vem dos registros fósseis, os quais revelam o aparecimento e o desaparecimento das espécies através do tempo geológico. O desaparecimento pode ocorrer de duas formas.

Primeiro, a espécie pode evoluir suficientemente de tal forma que os indivíduos não são mais reconhecidos como pertencentes ao mesmo taxon que os seus ancestrais e recebem um nome científico diferente. A extinção verdadeira não aconteceu, e tais situações são denominadas de pseudoextinção. Segundo, a população pode cessar de existir, em cujo caso o seu desaparecimento do registro fóssil é um caso de extinção verdadeira. Quanto mais detalhada é a resolução do registro fóssil, maior é a probabilidade de se distinguir entre os dois.

Quando a extinção verdadeira pode ser demonstrada, as durações de vida das espécies nos registros fósseis variam de acordo com o taxon, mas ela geralmente cai no intervalo de 1 a 10 milhões de anos. Deste modo, em média, a probabilidade de que uma espécie particular se torará extinta no período de um único ano (a taxa de extinção de fundo) está no intervalo de variação geral de 1 em 1 milhão até 1 em 10 milhões. Se, como as estimativas conservativas mostram, uma ordem de 1 a 10 milhões de espécies 
habitam a Terra, isto significaria cerca de 1 extinção de espécie por ano para a taxa de fundo.

\section{RELATO}

As extinções em massa ocupam o outro extremo do espectro. As catástrofes naturais podem causar o desaparecimento de uma proporção substancial de espécies local ou globalmente, dependendo da gravidade e da extensão geográfica da catástrofe. Tais catástrofes podem incluir secas prolongadas, furacões de grande intensidade e erupções vulcânicas. As mudanças no clima determinam as condições físicas e a estrutura do habitat, que são críticos para o bem estar de qualquer população. Através da longa história da Terra, as mudanças no clima global aconteceram pelo deslocamento dos continentes com as mudanças associadas na circulação oceânica.

Quando as barreiras físicas à dispersão impedem que as distribuições das espécies sigam o deslocamento dos cinturões de clima, as populações locais podem extinguir-se, sendo substituídas por outras que são mais bem adaptadas para sobreviver no novo clima e tipo de habitat. As mudanças locais no clima e no habitat acontecem pela mudança nas formas da terra, as quais podem criar sombras de chuva e redirecionar a drenagem dos rios. Para as espécies endêmicas, essas mudanças podem levar à extinção. Atualmente, a queima de madeira e combustíveis fósseis está aumentando a concentração de dióxido de carbono na atmosfera, e por meio disso aumentando a temperatura da Terra através do tão conhecido efeito estufa.

Essa mudança antropogênica no clima, que pode chegar de 2 a 6 graus celsius, é provável causar a extinção em muitas espécies, particularmente plantas, com tolerâncias de temperaturas estreitas. As áreas maiores suportam populações maiores, as quais são menos suscetíveis à extinção do que as pequenas populações por eventos catastróficos de pequena escala ou por variações aleatórias no tamanho da população. Apenas devido ao acaso, cada população apresenta variações nos nascimentos e nas mortes durante qualquer período particular. Isto causa o que é conhecido como variação estocástica ou "randômica" (aleatória) no tamanho da população. A magnitude dessa variação oscila inversamente com o número de indivíduos na população.

As populações muito pequenas, tais como aquelas isoladas em fragmentos restritos de habitat adequado, e é particularmente problemática para espécies como os grandes predadores, que têm densidades populacionais baixas. Outra forma pela qual uma pequena população pode ter sua probabilidade de extinção aumentada, é pela redução da variação genética da população. Menos indivíduos contêm uma proporção menor da variação genética total de uma população maior. Ademais, o endocruzamento (acasalamento entre parentes próximos) tende a reduzir a variação genética. Quando uma população atravessa um período de pequeno tamanho populacional e, em resultado, apresenta uma diversidade genética reduzida, é dita ter passado por um gargalo (bottleneck).

Em consequência, pequenas populações com baixa diversidade genética podem não ter a capacidade de responder a mudanças rápidas no ambiente, que podem favorecer alguns genótipos em alguns anos e outros genótipos em outros anos. A solução simples para manter a população de uma 
espécie particular é garantir a existência de uma área suficiente de habitat adequado que possa ser mantida livre de competidores invasores, predadores e patogenias. Na prática, o projeto de tais reservas deve levar em conta os requisitos ecológicos da espécie e o tamanho mínimo de uma população que possa se autossustentar em face de variações ambientais. Isto é chamado de população mínima viável ou MVP (minimum viable population).

A MVP deve ser grande o bastante para permanecer fora do perigo da extinção estocástica que acontece através de eventos aleatórios. A população também deve estar suficientemente espalhada, de forma que eventos de calamidades locais tais como furacões e incêndios não possam afetar a espécie inteira. Ao mesmo tempo, algum grau de subdivisão populacional pode prevenir uma epidemia de espalhar-se de uma parte da população para outra. A garantia de habitats adequados torna-se mais complexa quando as populações têm diferentes requisitos de habitat durante diferentes estações ou quando ela executa migrações sazonais de larga escala.

O problema é complicado, contudo, devido ao rápido crescimento da população humana, pela crescente exploração dos produtos da floresta, e pela conversão de florestas em agricultura. Esta exploração é justificada pela legítima necessidade de alimentar pessoas e gerar receitas de exportação para o desenvolvimento econômico. Deste modo, o preço da conservação está subindo rapidamente em grande parte do mundo, e muitos dos países em desenvolvimento são incapazes de pagar a conta. Mesmo quando as terras são separadas no papel, muitos países não têm dinheiro para protegê-las dos grileiros, caçadores e políticos egoístas que podem fornecer licenças de mineração e desmatamento em terras protegidas de forma a auferir benefícios de curto prazo. Por estas razões, a conservação deve ser um esforço internacional.

Em muitos casos, as fronteiras das reservas biológicas são ditadas pela área de terra disponível e por considerações econômicas: basicamente, tudo o que pode ser feito é separar o que quer que permaneça num estado relativamente original. Em outras situações, aqueles que projetam a reserva podem ter mais liberdade para decidir como desenhar as fronteiras de um parque ou outro tipo de reserva. Aqui, vários princípios ecológicos consequentes da teoria da biogeografia insular ajudam os planejadores a chegar à melhor solução para o problema da fronteira. Há dois princípios de conduta: a relação áreaespécie e o efeito de borda.

As áreas maiores sustentam mais espécies do que as áreas menores porque grandes populações de espécies individuais reduzem a extinção estocástica, promovem a diversidade genética dentro das populações e as protegem contra perturbações. As pontas devem ser minimizadas porque os efeitos de alteração de habitat estendem-se por alguma distância além da área diretamente afetada. De acordo com estas considerações, quando as reservas devem ser cortadas de áreas de habitats uniformes, como uma larga extensão de floresta tropical úmida maior é melhor do que menor, uma área grande é melhor que várias pequenas que somem o mesmo tamanho corredores conectando áreas isoladas são desejáveis, e áreas circulares são melhores do que áreas alongadas com muitas fronteiras.

Contudo, enfrentando a escolha entre uma única grande área de habitat uniforme e várias 
pequenas áreas de diferentes habitats, os planejadores devem lembrar-se de que as pequenas áreas frequentemente contêm um número total maior de espécies entre elas por causa das espécies endêmicas encontradas em um habitat mas não em outros. Dentro de uma ilha ou continente podem ocorrer muitos trechos isolados de habitats (topos das montanhas, lagos, rios, brejos, fragmentos de florestas nun cerrado), e não extensões contínuas.

As espécies características de tais habitats estariam distribuídas fragmentariamente, mesmo que ocupassem todos os fragmentos de um mesmo habitat. Existe, frequentemente, um motivo adicional para a fragmentação: as espécies ocupam somente certos trechos de um habitat. As partes separadas de um habitat funcionam, na verdade, como ilhas, no sentido de que as espécies a elas confinadas ficam sujeitas aos caprichos da imigração e da extinção. São mais ou menos equivalentes as listas de espécies existentes em diferentes áreas, dentro de uma grande e contínua extensão do habitat? Se o são, o trabalho do conservacionista será simplificado, no sentido de encontrar um local adequado, destinado a estabelecer uma reserva natural. Uma grande reserva deve ser suficiente para salvar a maioria da biota característica de um habitat.

O local para a reserva poderia ser escolhido no sentido de evitar áreas marcadas para o seu desenvolvimento, sem sacrificar o valor devido à conservação. Se as espécies são distribuídas em fragmentos dentro de um habitat, são necessárias reservas múltiplas, destinadas a preservar a biota do habitat, mesmo em curto prazo. A localização dessas reservas se torna ainda mais crítica, pois devem ser escolhidas cuidadosamente, de forma a conter as populações da maioria das espécies que ocorrem no habitat. A distribuição dos fragmentos deste último tipo, no entanto, é mais comum nos trópicos do que nas zonas temperadas.

A magnitude dessa fragmentação tropical (e dos problemas que ela apresenta aos conservacionistas), tem sido insuficientemente apreciada. Muitos pesquisadores de zona temperada estão desinformados sobre a fragmentação característica da zona tropical - e relutam em admiti-la por não encontrarem explicação para ela; ou então desprezam, sem muitas considerações, os casos relatados, considerando-os talvez artifícios de pesquisas biológicas inadequadas, ou frutos de sutileza deficiente no preenchimento dos requisitos ecológicos. Nos trópicos - especialmente nas áreas tropicais ricas em espécie - muitas espécies de pássaros estão distribuídas fragmentariamente em relação ao habitat disponível.

Explicações semelhantes são baseadas em fragmentações anteriores do próprio habitat (por exemplo, Pleistoceno posterior), equilíbrio imigração-extinção, e bloqueios competitivos. Cada um dos fatores é mais propenso a produzir fraturas nos trópicos do que nas zonas temperadas, e os dois últimos têm maior relevo nas comunidades ricas em espécies.

Uma conclusão prática para os conservacionistas interessados no futuro de um tipo de habitat tropical, detentor de flora ou fauna especiais, é que pode não ser suficiente separar um determinado pedaço, mesmo grande, do habitat. Ao contrário, pode ser mais adequado empregar esforços para obter um inventário de espécies em um local específico, certificando-se, porém, de que o local contém as populações da maioria das espécies endêmicas do habitat. 


\section{CONSIDERAÇÕES FINAIS}

A fragmentação apresenta, adicionalmente, o seguinte filema difíci para os conservacionistas: vamos supor que considerações de ordem política limitem a área total do habitat, que pode ser destinada a refúgios. Para salvar espécies, qual será a alocação ótima dessa área, e qual parte deverá ser alocada para cada refúgio individual? Opções extremas de estratégia seriam ou allocar toda a área para um único refúgio grande, ou dividi-la em vários pequenos refúgios.

Uma razão em favor do argumento de que os refúgios individuais sejam os maiores possíveis, é que algumas espécies necessitam requisitos mínimos de área, e também que as mais necessitadas de refúgio para a sua sobrevivência tendem a requerer maiores áreas. Entretanto, a distribuição das fragmentações pode contestar a alocação de toda uma área disponível para formar um único grande refúgio. É pouco provável que os fragmentos de todas as espécies que necessitam proteção possam coincidir. Vários refúgios em diferentes locações podem ser necessários, destinados a abrigar fragmentos de todas as espécies críticas representadas.

A necessidade de refúgios múltiplos aparecerá, especialmente naqueles casos onde a distribuição das fraturas é devida a bloqueios competitivos -, nestes casos, serão necessários refúgios múltiplos para suportar as diferentes espécies ou combinações de espécies. No caso de existir uma limitação prévia em relação à área disponível para um sistema de reserva, é aconselhável buscar um compromisso entre a necessidade de refúgios individuais grandes e de refúgios múltiplos.

Atualmente, muitas espécies estão divididas em fragmentos por várias razões. A fragmentação é exagerada nos trópicos, comparada às zonas temperadas, sendo desproporcionalmente mais marcante nas áreas com faunas mais diversificadas. A apreciação das fraturas é essencial na previsão de sistemas de reservas.

\section{REFERÊNCIAS}

ALMEIDA, J. R.; AQUINO, A. R.; ARAUJO, G. H. S.; GUENA, A. M. O.; RIOS, E. S.. Curva espécie/área para avaliação de recurso ambiental. Revista Brasileira de Pesquisa e Desenvolvimento, v.6, p.131-134, 2004.

BAUMOL, W. J.; OATES, W. E.. The use of standards and prices for protection of the environment. In: BOHN, P.; KNEESE, A. V.. The economics ofenvironment. MacMillan Press, 1971.
BUARQUE, C.. A desordem do processo: o fim da era dos economistas e a construção do futuro. 2 ed. São Paulo: Paz e Terra, 1990.

GUAZELLI, M. R.. O problema da poluição sob o ângulo econômico. Ambiente, v.6, n.1, p.60-64, 1992.

A CBPC - Companhia Brasileira de Produção Científica (CNPJ: 11.221.422/0001-03) detém os direitos materiais desta publicação. Os direitos referem-se à publicação do trabalho em qualquer parte do mundo, incluindo os direitos às renovações, expansões e disseminações da contribuição, bem como outros direitos subsidiários. Todos os trabalhos publicados eletronicamente poderão posteriormente ser publicados em coletâneas impressas sob coordenação da Sustenere Publishing, da Companhia Brasileira de Produção Científica e seus parceiros autorizados. Os (as) autores (as) preservam os direitos autorais, mas não têm permissão para a publicação da contribuição em outro meio, impresso ou digital, em português ou em tradução. 